\title{
THE STUDY OF THE RELATIONSHIP AMONG ENVIRONMENTAL COGNITION, ATTITUDE, SENSITIVITY, AND BEHAVIOR: THE CASE OF AN ECO-RESORT ISLAND
}

\author{
HAN-SHEN CHEN ${ }^{1,2}$ \\ ${ }^{1}$ School of Health Diet and Industry Management, Chung Shan Medical University, Taiwan. \\ ${ }^{2}$ Department of Medical Management, Chung Shan Medical University Hospital, Taiwan.
}

\begin{abstract}
This study discussed the relationship among environmental cognition, attitude, sensitivity, and behavior based on the concept of ecotourism. Structured questionnaires were utilized to investigate participants' traveling experiences in the Green Island, Taiwan. A total of 750 questionnaires were issued to generate 476 valid samples with $63.4 \%$ of response rate. The results showed that three out of five causal paths were significantly supported with statistical evidences. Environmental cognition had a significant effect on environmental sensitivity while environmental attitude and environmental sensitivity appeared significantly effect on environmental behavior. Meanwhile, the results discovered that the relationship between tourists' environmental cognition and behavior was not yet found in this study. In addition, this research also verified the indirect influence of environmental sensitivity on environmental behavior. That is, the more the tourists understand the meaning of ecotourism, the higher their sensitive levels about the environment are expected.

Keywords: eco-resort island, environmental attitude, environmental behavior, environmental cognition, environmental sensitivity.
\end{abstract}

\section{INTRODUCTION}

Based on the statistics provided by UNWTO (World Tourism Organization), the global tourism industry is growing at a rate of $4 \%$ annually. Hence, tourism has become one of the major focusing industries, which sustain the regional development in many countries $[1,2]$. The increase of demands on tourism resources, change in consumer behavior, and enhancement in environmental protection awareness strengthen the concept of ecotourism. The 'ecotourism' was first used by Hetor Ceballors and Lascurain in 1983. They were supposed to make people give an attention to protecting and improving the natural environment, after traveling in those less polluted area [3]. Ecotourism has become a vital part of sustainable community development and at present is the fastest growing sector of the tourism industry [4]. In Asia-pacific, ecotourism industry is growing continuously at a rate of 10-25\% per year. Especially, the rapid growth in island tourism has drawn scholars' and the experts' attention to relative studies [5]. However, due to the limitations of traffic, usable turf, economic type, and culture differences, the tourism development plans of an eco-resort island must be thoroughly evaluated with consideration of many facets such as ecology, economy, and society sustainability.

Green Island, which is located on south-east Pacific Ocean of Taiwan, was formed of volcanic rocks and gravels, which have created a complex topography. The road around the island is about $20 \mathrm{~km}$, and the island's area is $16.2 \mathrm{~km}^{2}$. Its beautiful marine landscape and rich biodiversity have attracted many tourists to visit, and it is one of the most beautiful outlying islands of Taiwan. The seashore recreation activities at Green Island have also recently increased by the rising tourism business, especially the diving business there. In 1995, Green 
Island was selected as an 'Eco-Resort Island' by the Pacific Economic Cooperation Council (PECC) and involved in the Pacific Ecotourism and Investment Prospects Project [6].

However, some environmental impacts came with the rapid growth in tourism, for instance, traffic jam, natural resource overexploitation, and tourists' misconducts. The influences include human beings, natural environment, cultural heritage, and pollutions. Therefore, local tourism bureau has to take the ecology, economy, and society sustainability, into account to minimize the possible impacts. The main purpose of this study is to ensure sustainable tourism growth under such concepts with consideration of ecosystem, biological diversity, climate change, and environmental protection.

In the study of ecotourism, many researchers agreed that the consisting influential variables of environmental behavior and their correlations are complicated. Some studies held different perspectives on correlations between environmental cognition and environmental behavior [7,8]. Therefore, the contribution of this study was to take environmental cognition as one of the variables to predict and explain tourists' intention of environmental behavior. Many studies revealed that environmental attitude is positively related to behavior intention [7,8]. Additionally, researches indicated that environmental sensitivity is one of the major factors that influence environmental behavior [9]. Thus, this study intended to examine environmental attitude and environmental sensitivity as dominated dimensions of the research framework. To sum up, this study investigated the tourists who visited Green Island, Taiwan, to understand their environmental cognition, attitude, sensitivity, and behavior after traveling. The results can provide useful information to local tourism bureau as well as tourism industry in promoting ecotourism and environmental protection.

\section{RESEARCH METHOD}

\subsection{Research framework}

The review of aforementioned literatures in environment studies found that most of these studies have researched on several subjects without examining a comprehensive model as a whole. Hence, an explicit review of the literature was performed to select the most appropriate method to measure each construct considered. The proposed model is shown in Fig. 1.

\subsection{Research hypotheses}

A variety of theoretical structures have been developed to help understand what motivates or constrains individual behaviors, many of which include relationships between attitudes,

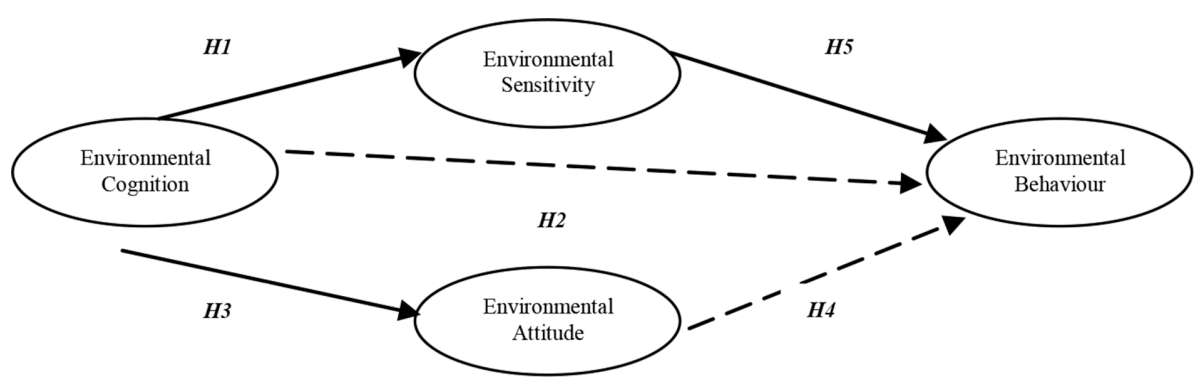

Figure 1: The proposed model. 
cognition, and behaviors [10, 11]. The links between these are not clear in all cases [12]. Depending on the situation and behavior being investigated though, attitudes have been shown to have strong impacts on behavior [12]. The impact of information on behavior is more unclear. Grob [12] found no relationship between factual cognition and environmental behavior. In some widely used behavioral theories, such as the Reasoned Action Approach, attitudes and beliefs have an indirect effect on behaviors. For example, the environmental behaviors of farmers in the USA have been shown to be influenced by their perception of environmental degradation and expectations about what the behaviors will accomplish, which directly affects their attitudes toward a given behavior [13].

Environmental sensitivity means a predisposition to acknowledge the intrinsic value of nature, cultivate an interest in learning about the environment, feel concerned for it, and love it on the basis of formative experiences. Many qualitative researches have discovered that environmental sensitivity is an important variable in environmental awareness and in the predisposition to take responsible environmental action, in which sensitivity is associated with particular kinds of significant life experiences [14]. Sun et al. [15] claim that environmental sensitivity, behavior constraint, and communal norms can significantly explain the level of sustainable purchasing behavior [15]. Thus, the assumptions of this study descripted as follows:

Hypothesis 1: Environmental cognition has a positive effect on environmental sensitivity. Hypothesis 2: Environmental cognition has a positive effect on environmental behavior. Hypothesis 3: Environmental cognition has a positive effect on environmental attitude. Hypothesis 4: Environmental attitude has a positive effect on environmental behavior.

Hypothesis 5: Environmental sensitivity has a positive effect on environmental behavior.

\subsection{Sampling and data collection}

This study investigated the tourists' perspectives of environmental cognition, attitude, sensitivities, and behavior on an ecotourism resort island, Green Island in Taiwan. A purposive sampling strategy was used to obtain the questionnaires. 750 questionnaires were placed on the front desk of 20 selected hotels and B\&B. The survey was conducted from July to August 2012.

The SPSS is utilized to analyze the descriptive statistic of gathered data. AMOS was used to perform confirmatory factor analysis, survey questions' reliability, constructs reliability, average variance extracted (AVE) of constructs' validity. Importantly, a structural equation modeling was built to test the causal relationships among constructs and proposed in the framework of this study.

\section{RESULTS}

\subsection{Respondents' profile}

First, a 44-item instrument was administered by survey questionnaire to 750 randomly selected tourists on-site and 543 samples were collected. After uncompleting checking, 476 samples were used for further analysis that contributed $63.4 \%$ of the response rate. According to demographic analysis on this study, the descriptive statistics showed that the ratio of male and female was $43.5 \%$ and $56.5 \%$, respectively. Almost two-third of respondents were married $(62.7 \%)$, followed by $37.3 \%$ of single respondents. In the analysis of 
participants' age, the group of 20-50 accounted for a considerable high ratio (80.3\%), and followed by the group of 51-60 years old (11.3\%). On the education level, over two-third of the respondents have bachelor or higher degree, accounting for $67.8 \%$, represented that Taiwanese commonly obtain high education. Finally, about $37.6 \%$ of participants reported that their household monthly income range was between US 1000 and US 1333 dollars, followed by US 667 to US 999 dollars (33.6\%).

\subsection{Confirmatory factor analysis and hypothesis test}

The data analysis was based on a two-step approach, proposed by Anderson and Gerbing [16], to perform confirmatory factor analysis on total sample structural equation model. After evaluating the fitness, the assessment model evaluation and causal analysis were examined. To simplify questionnaire items so that AMOS can be applied, six behavioral items were directly used as the input data. The results indicated that each of the cognition, sensitivity, and attitude dimension existed two factors. Environmental cognition dimension involved sustainability and functionality factors; environmental sensitivity dimension included 'the level of concern on the environment' and 'the level of concern on environment functionality'; environmental attitude related to environmental cognition and utilization factor.

The results of the structural model are shown in Table 1. Each construct items standardized factor loadings were within the range of $0.60-0.84(p<0.01)$. Some individual items' reliability $R^{2}$ were not within the range of $0.34-0.70$; this moderately satisfy the recommended [17] reliability of 0.3 . The four constructs composite reliability was all complied with the proposed [18] level of $>0.5$. Each construct's AVE was close to the threshold requirements. Overall, the statistical evidence supported the result that the structural equation modeling met the criteria of good model fit. As a result, the statistics of the assessment model fitness reached satisfactory level, $\chi^{2}=37.6(\mathrm{df}=20), \chi^{2} / \mathrm{df}=1.879$, GFI $=0.983$, $\mathrm{AGFI}=0.962, \mathrm{RMR}=0.013, \mathrm{RMSEA}=0.043, \mathrm{CFI}=0.987, \mathrm{NNFI}=0.972, \mathrm{NFI}=0.973$, $p<0.01$. The evidences of results revealed that the fitness of the constructed structural equation was good. By assessing the positive and negative significant parameter estimates, the hypothesis tests and relation intensity can be determined.

The results of path analysis indicated that $H 1, H 3$ and $H 5$ were supported by the statistical evidence $(p<0.01)$, while $H 2$ and $H 4$ presented non-significant. The results also indicated that the total effect of environmental cognition to environmental sensitivity and environmental attitude were 0.677 and 0.866 , respectively. The total effect of sensitivity to behavior was .581 . Although the standardized factor loading of attitude to behavior was 0.618 , the non-significant result was found through this path.

\section{CONCLUSIONS}

\subsection{Conclusion}

Developing ecotourism will inevitably impact on the local environment and its ecosystem. However, the impacts can be diminished by suitable management strategies. This study investigated Green Island, Taiwan, as a research site and thoroughly discussed the participants' perspectives of environmental issues. The overall outcome revealed that tourists' environmental cognition has influenced on environmental sensitivity, environmental attitude, and environmental behavior. Thus, an integrated ecosystem behavior model was built and verified based on the evidence provided by this study. 
Table 1: The results of structural model $(n=476)$.

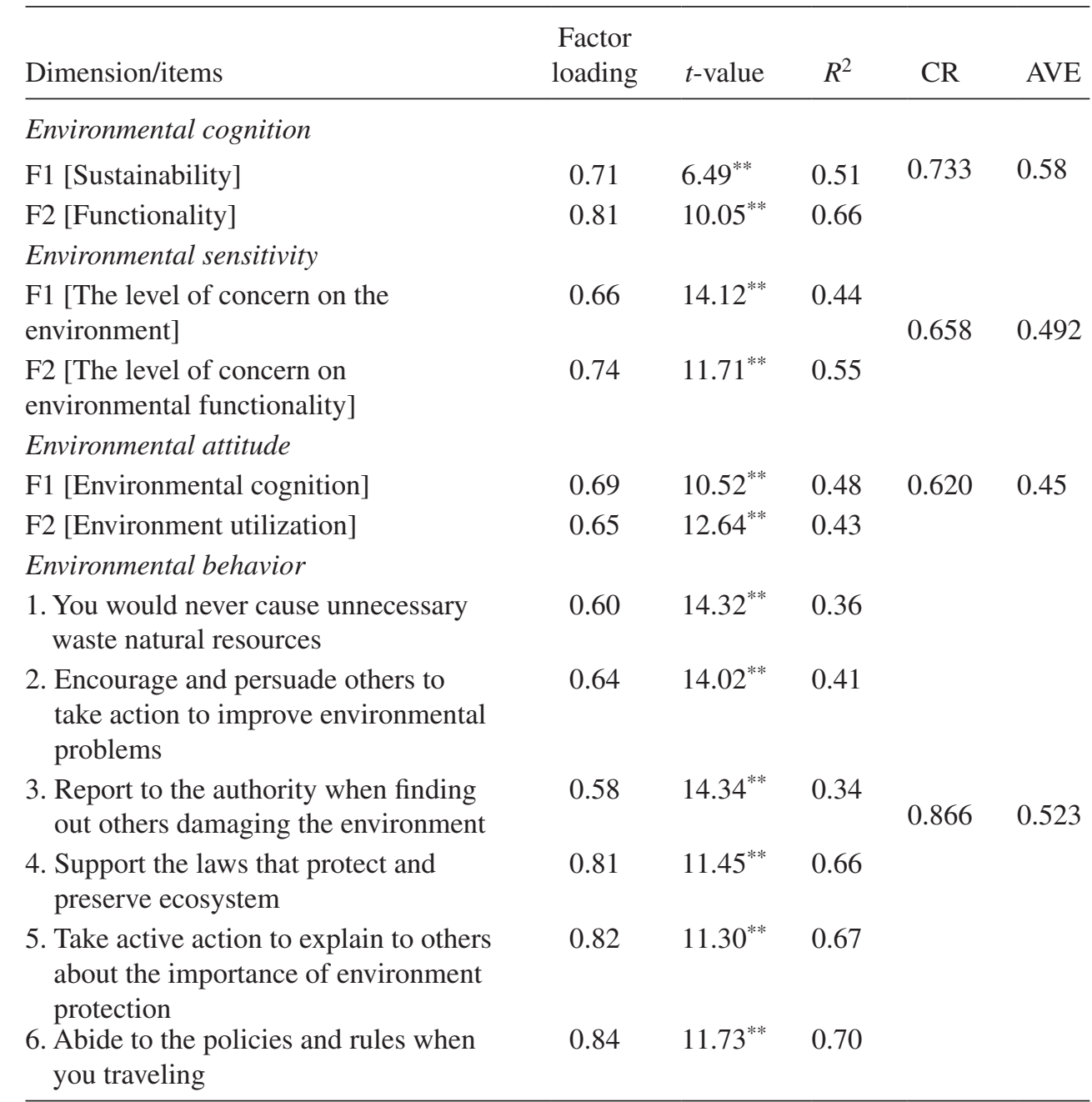

Note: $\chi^{2}=37.6(\mathrm{df}=20), \chi^{2} / \mathrm{df}=1.879, \mathrm{GFI}=0.983, \mathrm{AGFI}=0.962, \mathrm{RMR}=0.013, \mathrm{RMSEA}=0.043$, $\mathrm{CFI}=0.987, \mathrm{NNFI}=0.972, \mathrm{NFI}=0.973,{ }^{* *} p<0.01$.

In theoretical stand point, some previous researchers pointed out many positive and negative impacts of developing ecotourism [19-22]; however, none of these studies has yet been focused on estimating the correlations among environmental cognition, sensitivity, attitude, and behavior. This study consolidates the aforementioned variables and built a causal model to understand tourists' preference on tour environment and their perspectives and behavior about environment protection. Moreover, one of the contributions of this study was to fulfill the research gap of the current studies in the ecotourism field that benefited both theoretically and practically. More importantly, the contribution of this research was to construct substantial references for tour organizers and people who work with tourism industry in developing usable strategies to protect natural resources while designing an eco-tour. Hence, the education lessons of eco-friendly such as eco concepts, environment protection acts, recycle 
demonstration, and green tour engagement were recommended to offer to tourists before starting an eco-tour.

The result of this study also showed that the tourists' environmental cognition was not affected on their environmental behavior, consisting with Chen and Yeh's study [9]. Accordingly, the relationship between environmental attitude and environmental behavior presented weakness that was confirmed with other studies [23,24]. The possible reason behind such phenomenon was that tourists may lack of awareness of how their behaviors would cause actual impacts in the environment.

Furthermore, this research verified the indirect effect of environmental sensitivity on environmental behavior; the indirect influence effectiveness was 0.527 . This result illustrated that the more the tourists understand ecotourism cognition, the higher their sensitivity to the environment was expected.

\subsection{Research limit and future research suggestion}

In tourism, ecotourism is considered as a niche market in comparing with other types of tourism. In ecotourism area, many researchers devoted to concentrate on how to minimizing the nature and environment impacts. In practice, the difficulty in collecting valid and usable data was found in this study. This study was only a cross-sectional study and intended to reduce the gap of current research. Due to the lack of long-term detail statistics, the population of ecotourists was not well defined. Therefore, sampling frame cannot be built for appropriate sampling method. Additionally, ecotourism is still a new rising concept in the tourism domain; long-term information is yet to be acquired with further studies. For future research, the topic of ecotourism is recommended to investigate longitudinally. The result would serve as a valuable reference to the governance authorities in promoting and developing ecotourism in other regions.

\section{REFERENCES}

[1] Brida, J.G. \& Risso, W.A., Tourism as a determinant of long-run economic growth. Journal of Policy Research in Tourism, Leisure and Events, 2(1), pp. 14-28, 2010. doi: http://dx.doi.org/10.1080/19407960903542276

[2] Dodds, R. \& Butler, R., Barriers to implementing sustainable tourism policy in mass tourism destinations. Tourismos, 5(1), pp. 35-54, 2010.

[3] Wang Huabin, \& Zhou Ling., The Development of Eco-tourism. Science Press, Beijing. pp. 254, 2000.

[4] Weinberg, A., Bellows, S. \& Ekster, D., Sustaining ecotourism: insights and implications from two successful case studies. Society and Natural Resources, 15(4), pp. 371-380, 2002. doi: http://dx.doi.org/10.1080/089419202753570846

[5] Wu, T.C., Accessing ecotourism development model for rural communities. Journal of Rural Tourism Research, 1(1), pp. 19-57, 2007.

[6] Sung, B.M., The planning of eco-tourism development in Green Island. Journal of Outdoor Recreation Study, 9(4), pp. 31-40, 1996.

[7] Lyons, E. \& Breakwell, G.M., Factors predicting environmental concern and indifference in 13 to 16-years-old. Environment and Behaviour, 26(2), pp. 223-238, 1994. doi: http://dx.doi.org/10.1177/001391659402600205

[8] Lin, M.R. \& Hsieh, Y.C., A study on the developmental factors of model environmental communities in central Taiwan. Journal of National Taichung Teachers College, 19(1), pp. 89-113, 2005. 
[9] Chen, S.L. \& Yeh, G.L., A study of environmental behaviours \& related influential factors - an example of the junior high school students in Pingtung area of Taiwan. Chinese Journal of Environmental Education, 1, pp. 13-30, 2002.

[10] Dunlap, R.E., Van Liere, K.D., Mertig, A.G. \& Jones, R.E., Measuring endorsement of the new ecological paradigm: a revised NEP scale. Journal of Social Issues, 56(3), pp. 425-442, 2000. doi: http://dx.doi.org/10.1111/0022-4537.00176

[11] Fishbein, M. \& Ajzen, I., Predicting and Changing Behavior: The Reasoned Action Approach. Taylor \& Francis: New York, 2010.

[12] Grob, A., A structural model of environmental attitudes and behavior. Journal of Environmental Psychology, 15(3), pp. 209-220, 1995. doi: http://dx.doi.org/10.1016/02724944(95)90004-7

[13] Reimer, A.P., Thompson, A.W. \& Prokopy, L.S., The multi-dimensional nature of environmental attitudes among farmers in Indiana: implications for conservation adoption. Agriculture and Human Values, 29(1), pp. 29-40, 2012. doi: http://dx.doi.org/10.1007/ s10460-011-9308-z

[14] Chawla, L., Significant life experiences revisited: a review of research on sources of environmental sensitivity. The Journal of Environmental Education, 29(3), pp. 11-21, 1998. doi: http://dx.doi.org/10.1080/00958969809599114

[15] Sun, Y., Song, J. \& Song, D., The empirical study on the factors influencing urban residents' environmental behaviors. Chinese Journal of Management, 9, pp. 144-150, 2012.

[16] Anderson, J.C. \& Gerbing, D.W., Structural equation modeling in practice: a review and recommended two-step approach. Psychological Bulletin, 103(3), pp. 411-423, 1988. doi: http://dx.doi.org/10.1037/0033-2909.103.3.411

[17] Jöreskog, K. G., Testing structural equation models. In K. A. Bollen \& J. S. Long (Eds.), Testing structural equation models, Newbury Park, CA: Sage. pp. 294-316,1993.

[18] Fornell, C. \& Larcker, D.F., Evaluating structural equation models with unobservable variables and measurement error. Journal of Marketing Research, 18(1), pp. 39-50, 1981. doi: http://dx.doi.org/10.2307/3151312

[19] Liu, J. \& Var, T., Resident attitudes toward tourism impacts in Hawaii. Annals of Tourism Research, 13(2), pp. 193-214, 1986. doi: http://dx.doi.org/10.1016/0160-7383(86)90037-X

[20] Long, T.P., Perdue, R.R. \& Allen, L., Rural resident tourism perceptions and attitudes by community level of tourism. Journal of Travel Research, 28(3), pp. 3-9, 1990. doi: http://dx.doi.org/10.1177/004728759002800301

[21] Allen, L.R., Hafer, H.R., Long, P.T. \& Perdue, R.R., Rural residents' attitudes toward recreation and tourism development. Journal of Travel Research, 31(4), pp. 27-33, 1993. doi: http://dx.doi.org/10.1177/004728759303100405

[22] Lankford, S.V., Attitudes and perceptions toward tourism and rural regional development. Journal of Travel Research, 32(3), pp. 35-44, 1994. doi: http://dx.doi. org/10.1177/004728759403200306

[23] Dunlap, E.R. \& Van Liere, K.D., The new environmental paradigm: a proposed measuring instrument and preliminary results. The Journal of Environmental Education, 9(4), pp. 10-19, 1978. doi: http://dx.doi.org/10.1080/00958964.1978.10801875

[24] Ostman, R.E. \& Parker, J.I., Impact of education, age, newspapers, and television on environmental knowledge, concerns, and behaviours. Journal of Environmental Education, 19(1), pp. 3-9, 1987. doi: http://dx.doi.org/10.1080/00958964.1987.10801954 